${ }^{1}$ С. Ю. Жукова, ${ }^{1}$ Б. В. Орехов, ${ }^{1,2}$ Е. В. Рахилина

${ }^{1}$ НИУ «Высшая школа экономики»

${ }^{2}$ Институт русского языка им. В. В. Виноградова РАН

(Россия, Москва)

syupuzhaeva@gmail.com,nevmenandr@gmail.com,rakhilina@gmail.com

\title{
ДИСКУРСИВНЫЕ ФОРМУЛЫ РУССКОГО ЯЗЫКА: ДИАХРОНИЧЕСКИЙ ПОДХОД*
}

Статья посвящена проблеме описания дискурсивных формул русского языка с позиции диахронии. Под дискурсивными формулами понимаются устойчивые, легко воспроизводимые изолированные конструкции, ср.: Еще бы! Не то слово! То-то же и под. Они служат ответными репликами в диалоге и в отличие от традиционных конструкций не содержат переменных внутри себя: свободным слотом для них становится предшествующая реплика другого говорящего. Важным аспектом описания дискурсивных формул является динамика их изменений во времени. В силу своей частотности, семантической опустошенности и прагматической нагруженности дискурсивные формулы так быстро появляются, исчезают и сменяют друг друга, что эти изменения видны даже на выбранном нами временном отрезке в 200 лет, который охватывает XIX-XX век. На базе статистического исследования, которое упорядочивает составленный нами список русских дискурсивных формул на временной оси, в статье последовательно анализируются примеры уходящих, новых и стабильных дискурсивных формул. На этих примерах исследуются механизмы возникновения новых формул, связанные с прагматикализацией (то есть превращением в идиоматичные выражения с прагматическим значением прежде композициональных сочетаний), а также причины старения формул и природа нестабильности их формы и семантики.

Ключевые слова: дискурсивные формулы, диахронические исследования, корпусная лингвистика, грамматика конструкций, Русский конструктикон, дискурс пьес.

\footnotetext{
${ }^{1}$ Работа выполнена при поддержке РФФИ (грант № 17-29-09154).
} 


\section{1. Введение: постановка задачи}

Одной из наиболее значимых лингвистических теорий XX века является теория Грамматики конструкций [Fillmore 1988; Fillmore, Kay 1992], согласно которой основной лингвистической единицей признается конструкция. При этом под конструкцией понимается «языковое выражение, у которого есть аспект плана выражения или плана содержания, не выводимый из значения или формы составных частей» [Рахилина, Кузнецова, 2010: 19], см. подробнее [Hoffmann, Trousdale 2013]. Разные конструкции различаются по своему синтаксису и семантике, так что можно говорить о типах конструкций и классификации конструкций, которая для русского языка предпринята в рамках проекта Русский конструктикон (подробнее см. Janda et al. 2018).

Согласно этой классификации, одним из важных и нетривиальных классов конструкций являются так называемые дискурсивные формулы (термин восходит к [Fillmore 1984]): законченные неоднословные реплики в диалоге в ответ на вербальный стимул собеседника, не обусловленный частной социально значимой ситуацией, ср. Не тут-то было!, Как же это? Вон оно как! и под. Структурно дискурсивные формулы (ДФ) включают в себя преимущественно частицы, союзы, местоимения, но также и исходно полнозначные, но десемантизированные слова.

Подробно особенности дискурсивных формул как конструкций рассмотрены в статье настоящего выпуска Трудов [Бычкова и др. 2018] на примере полисемичной формулы да ну. Там приводятся сходные классы языковых явлений и близкие термины $^{1}$, а также дается синхронный взгляд на семантико-синтаксические свойства формул, которые маркируются прежде всего интонацией и жестикуляцией. Пример $\partial а$ ну, mbl что и других формул показывает, что все особенности формул мотивированы дискурсивным характером их значения, возникшего в результате выветривания семантики и потери композициональности исходной для формулы сложной языковой единицы (словосочетания).

Именно этот, диахронический аспект функционирования в языке дискурсивных формул (ДФ) будет нас интересовать. Он тоже имеет свои особенности для дискурсивных формул по сравнению с обычными конструкциями: в их случае конструкционализация заканчивается образованием не единицы со значением из универсального грамматического набора, а единицы с особым, прагматическим значением - эмфатического согласия, одобрения, отрицания и проч. Эмфатичность и оценочность этих единиц становится причиной довольно быстрых, наблюдаемых даже на протяжении короткого промежутка времени, диахронических изменений в этих конструкциях, и это свойство нужно учитывать при их описании: в частности, оно способствует вариативности ДФ - большей, чем обычных конструкций, и в целом значительной нестабильности этих единиц. Нашей задачей было «измерить» эту нестабильность, понять ее природу и проиллюстрировать

${ }^{1}$ См., например, formulae [Coulmas 1981], conversational routines [Aijmer 1996], pragmemes [Mеy 2001], formulaic sequence [Wray 2002], коммуникативы [Шаронов 1996] и др. 
соответствующие лингвистические процессы примерами изменений, которым подверглись конкретные формулы русского языка.

Таким образом, наша работа укладывается в широкий круг исследований, которые посвящены изучению микродиахронии русского языка и начинались с классических трудов [Булаховский 1948; Виноградов, Шведова 1964]. По большей части тщательному изучению подвергались грамматические категории (см, в частности, RusConstr 2017), недавнюю статью [Падучева 2018] на материале романа Л. Н.Толстого «Анна Каренина». Между тем значительная часть работ, посвященных языку периода А С. Пушкина, показывает, что не только грамматические, но и «лексические и прагматические особенности речи $<\ldots>$ очень сильно изменились за последние 160-170 лет» [Добровольский 2001], что может выражаться в порой незаметных для читателя семантических сдвигах [Пеньковский 2005], [Зализняк Анна 2012] и др.

В последнее время задача исследования микродиахронических изменений решается с привлечением корпусного материала, ср. [Даниель, Добрушина 2016], предпринимаются попытки выявления семантических сдвигов на основе больших массивов данных [Kuzmenko, Kutuzov 2017], создан и специальный корпус языка XIX века [Рахилина и др. 2016, Рахилина 2017]. Все эти публикации служат методологической основой для нашей микро-диахронической работы с ДФ как лексико-грамматическими единицами.

В диахронических исследованиях в рамках грамматики конструкций в зоне внимания в конечном итоге всегда оказывается история отдельной конструкции [Hilpert 2013]. Однако ДФ представляют более гомогенный класс, важный для изучения таких системных процессов, как грамматикализация и прагматикализация [Hopper, Traugott 2003]. Как кажется, для него можно выделить определенные закономерности, которые могут быть видны даже на достаточно коротком временном промежутке.

С этой целью мы полуавтоматически составили список ДФ русского языка и затем провели статистический анализ этого списка в диахронии, определив динамику частотности каждой формулы по Национальному корпусу русского языка (НКРЯ) в течение примерно последних двух веков (то есть начиная с XIX века). Эти подготовительные этапы нашей работы будут коротко описаны в разделе 2 . Статистика показала, что несмотря на то, что мы взяли такой короткий временной интервал, внутри него в нашем списке есть «новые», то есть недавно возникшие формулы и «старые», уходящие или даже уже ушедшие из языка. В разделах 3 и 4 мы рассмотрим примеры таких формул и проанализируем ход изменений, которые они претерпевают, на материале Национального корпуса русского языка. Раздел 5 посвящен формулам, которые стабильно присутствуют в русском языке на протяжении двух веков. Раздел 6 Заключение подводит итоги нашего исследования. 


\section{2. Дискурсивные формулы: динамика изменений в ДФ по данным НКРЯ}

Процедура создания списка ДФ подробно описана в [Пужаева и др. 2018]. Вначале была проведена ручная разметка более 60 пьес, которая послужила основой для дальнейшего машинного обучения. Пьесы были выбраны в качестве исходного материала, поскольку они в большей степени имитируют разговорную речь. После нескольких этапов улучшения автоматического модуля по извлечению ДФ из текстов мы применили готовую программу к 420 пьесам XIX-XXI вв., взятым из двух корпусов драматических текстов [Lubimovka 2018, Russian Drama Corpus 2018].

Первоначально в таблице, созданной после автоматической обработки материала, было около 3000 структурно устойчивых единиц, которые в дальнейшем были классифицированы с точки зрения принадлежности их к синтаксическим конструкциям, этикетным выражениям и иным коллокациям. Собственно дискурсивных формул ${ }^{2}$, у которых на первый план выходит прагматическая функция, оказалось не так много: учет вариативности и объединение их по структурному и семантическому сходству позволил сократить список, в котором сейчас осталось 925 единиц. Понятно, что этот список неоднородный - и в формальном и в семантическом отношении, и требует дальнейшей работы: систематизации, классификации и подробного анализа. Однако и теперь в нем явно просматривается противопоставление устаревших и новых, недавно появившихся ДФ.

Отправной точкой нашего исследования был гипотеза о том, что даже на таком коротком этапе, как 200 лет, мы увидим динамику изменения этих единиц, потому что они шаблонны как реплики и обладают высокой частотностью, и это должно ускорять процесс их контрукционализации - а точнее прагматикализации.

Материалом для проверки этого предположения послужила текстовая коллекция Национального корпуса русского языка (НКРЯ). Благодаря богатой метатекстовой разметке мы знаем дату создания каждого текста и можем расположить найденные в этих текстах ДФ на временной шкале.

Поиск по текстам производился автоматически. Мы использовали список ДФ (полученный на предыдущем этапе), и искали их вхождения в текстах таким образом, чтобы они оказались между знаками препинания, традиционно отграничивающими предложение или вставную конструкцию (таким образом, сочетания внутри запятых как знаков пунктуации не учитывались). Такое дополнительное

2 Заметим, что наши формулы часто очень многозначны, и в разных значениях «пересекают границы» собственно дискурсивных, представляя в других своих значениях единицы другого плана. В этом отношении ручная «чистка» итогового списка при любом, даже самом высоком качестве программы, будет неизбежной. Хорошей иллюстрацией может служить формульное сочетание скажсите пожалуйста, которое прежде всего является известной застывшей формулой вежливости в вопросе, однако ввиду своего дальнейшего развития приобрело круг дискурсивных употреблений: - Скажите лучше, что за дама была с Евлампием. - А это Евлампий? - Он. Скажите пожалуйста! Важный, со спины и не подумаешь, что лакей. [Леонид Юзефович. Дом свиданий (2001)]. 
ограничение на поиск накладывалось, чтобы избежать смешений, представленных в парах типа (1) и (2):

(1) - Ну что ж, - сказал он хрипло, - давай бог. Давай, давай. Может быть, тут тебя постигнет удача. Не вылло с романом, кто знает, может быть, с пьесой выйдет. [М.А. Булгаков. Записки покойника (Театральный роман) (1936-1937)].

Ср. Обычно ей нравились читающие люди. Но в случае Жени-сана чтение имело непредсказуемые последствия. - Разве есть такие книжки? - Кмо знает? И вообще - все это неважно. Важно, чтобы с Марсиком не случилось ничего плохого. Костик был полностью согласен с мамой. [М.С. Аромштам. Мохнатый ребенок (2010)].

(2) Её работа (Елена Андреевна) в "Дяде Ване» Льва Додина, без сомнения, стала одним из важных событий прошедшего фестиваля. Они с Соней ровеснищы, почти сёстры. [Легкое дыхание (2004) // «Экран и сцена», 2004.05.06].

Ср. - Tы уверен, что это она? - проговорил «священник». Его лицо попрежнему было скрыто капюшоном. - Без сомнения! Она рождена под знаком числа света. Четырежды семь, я это проверил. Она рождена в иарском доме, в ее жилах течет священная кровь... [Наталья Александрова. Последний ученик да Винчи (2010)].

Для каждой ДФ фиксировалось только одно вхождение в тексте: если ДФ попадалась в одном документе большее число раз, остальные вхождения игнорировались: такой подход был избран для того, чтобы исключить влияние индивидуального стиля автора. При этом абсолютное число найденных в текстах за определенный год ДФ делилось на совокупное число слов в документах за этот год. Этот способ нормализации выбран потому, что вероятность появления ДФ зависит именно от объема корпуса, а не от числа документов. Иными словами, в большом корпусе, состоящем из ограниченного числа длинных текстов ДФ встретить проще, чем в большом корпусе, включающем много коротких произведений. Разумеется, это утверждение справедливо не всегда, но как выяснилось, оно хорошо соотносится со спецификой жанрового состава НКРЯ.

Так как некоторые ДФ довольно редки, а деление их вхождений производилось на число на много порядков превышающее количество этих вхождений, в итоге получалась дробь с длинным «хвостом» цифр после запятой, из которых первые несколько были нулями. Для удобства мы умножили получившийся результат на 1000000.

Полученные данные подтвердили наше предположение о высокой динамичности этих единиц: значительную часть ДФ из списка можно отнести к категории устаревших и устаревающих (да что такое, как ты смеешь, сделай милость), в то же время мы видим новые единицы, появившиеся в русском языке только конце XX - начале XXI века (без проблем, все в порядке, так не бывает), 
и наконец, - небольшую группу ДФ, которые употребляются с той или иной мерой постоянства на протяжении практически всего анализируемого периода (что такое, что это, как же). Рассмотрим примеры каждого из типов.

\section{3. Устаревшие и устаревающие формулы}

Группу, занимающую по объему около $40 \%$ от всех формул, составляют устаревшие и устаревающие формулы - те, которые стабильно не употребляются на протяжении хотя бы последних четырех десятилетий или имеют тенденцию к уменьшению количества употреблений, хотя продолжают фигурировать в текстах вплоть до XXI века, такие как тьфу, пропасть; сделай милость; почем я знаю и проч. Они служат яркой лингвистической характеристикой классических текстов середины XIX века и приемом стилизации для писателей следующих поколений, которые обращаются к минувшей эпохе, ср. (3):

(3) Фома попробовал подтянуть сипльм волчьим тенорком, сбился и сбил Маманю. - Тьфу ты, пропасть! - раздраженно плюнула она. - Такую песню испортил! [Сергей Осипов. Страсти по Фоме. Книга вторая. Примус интер парэс (1998)].

Примерно в 20\% случаев, как показывает материал, устаревание конструкций происходит за счет устаревания или существенного семантического изменения исходно полнозначных слов в их составе. Хорошим примером такого рода может служить вопросительное слово почем, которое до сих пор существует в разговорной речи в значении 'сколько стоит / какая цена', но устарело и исчезло в современном языке в значении 'почему'.

Действительно, если в конце XVIII — начале XIX в. мы видим разнообразные варианты формул с элементом почем: почем знать, почем знаешь, я почем знаю, почем угадать, почем ты знаешь и т.д., и они оказываются более употребительными, чем слово почем в значении 'сколько стоит', то к середине XX в. ситуация

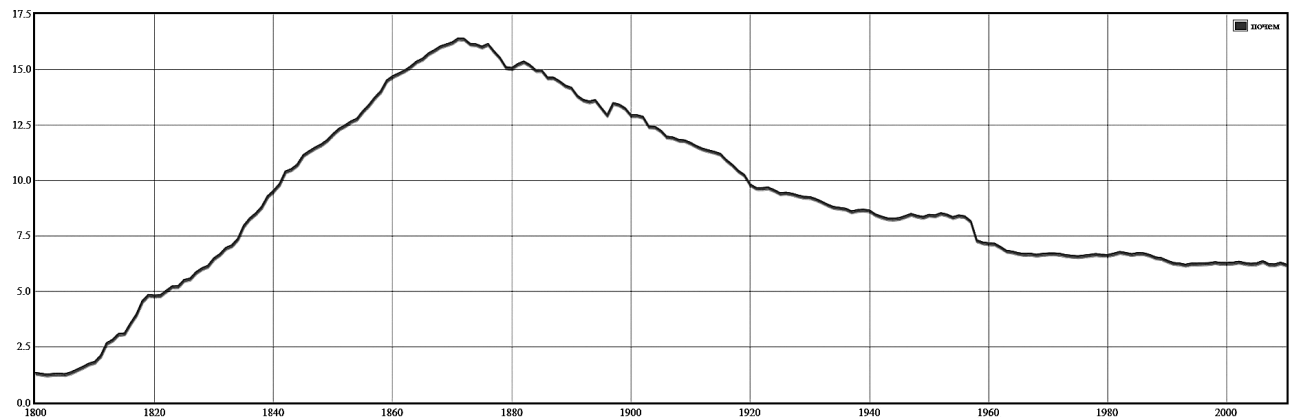

Рис. 1. Частотность употребления слова почем

Здесь и далее поиск производится с учетом введенного ранее ограничения: ДФ с двух сторон ограничена знаками конца предложения. К графикам применена функция сглаживания 
в корне меняется: более редким становится формульное употребление и на первый план выходит использование этого слова в значении 'сколько стоит'. (Одновременно появляется и быстро набирает частотность также некомпозициональное фразеологизованное сочетание почем зря).

Между тем сама формула в этом случае сохранилась: место устаревшего значения вопросительного почем заняло другое вопросительное слово откуда в значении 'почему', так что на смену формуле почем я знаю (рис. 2) пришла формула откуда я знаю:

(4) Ты скажи, куда восемьсот рублей делись? - Почем я знаю? Разве я знаю, куда вы тратите? [И. А. Гончаров. Обломов (1859)].

Отец, когда умер Достоевский? - Откуда я знаю? - сказал мистер Браун, ульгбаясь. [Б. Б. Вахтин. Портрет незнакомца (1966)].

Заметим, что для вопросительного откуда семантика причины тоже не единственная - исходным для него является пространственное значение исходной точки (ср.: откуда X пришел?). Вообще говоря, сдвиг в причинную зону из пространственной в контексте знать вполне естествен, потому что для знать источник знания и является причиной-основанием. Однако он сопровождается повышенной эмфатичностью: классические вопросительные контексты в этом случае выражают вопрос-недоверие, когда сообщенная собеседником информация входит в конфликт с презумпциями говорящего. Соответствующая дискурсивная конструкция (по форме - риторический вопрос говорящего к себе) с семантикой 'не знаю'
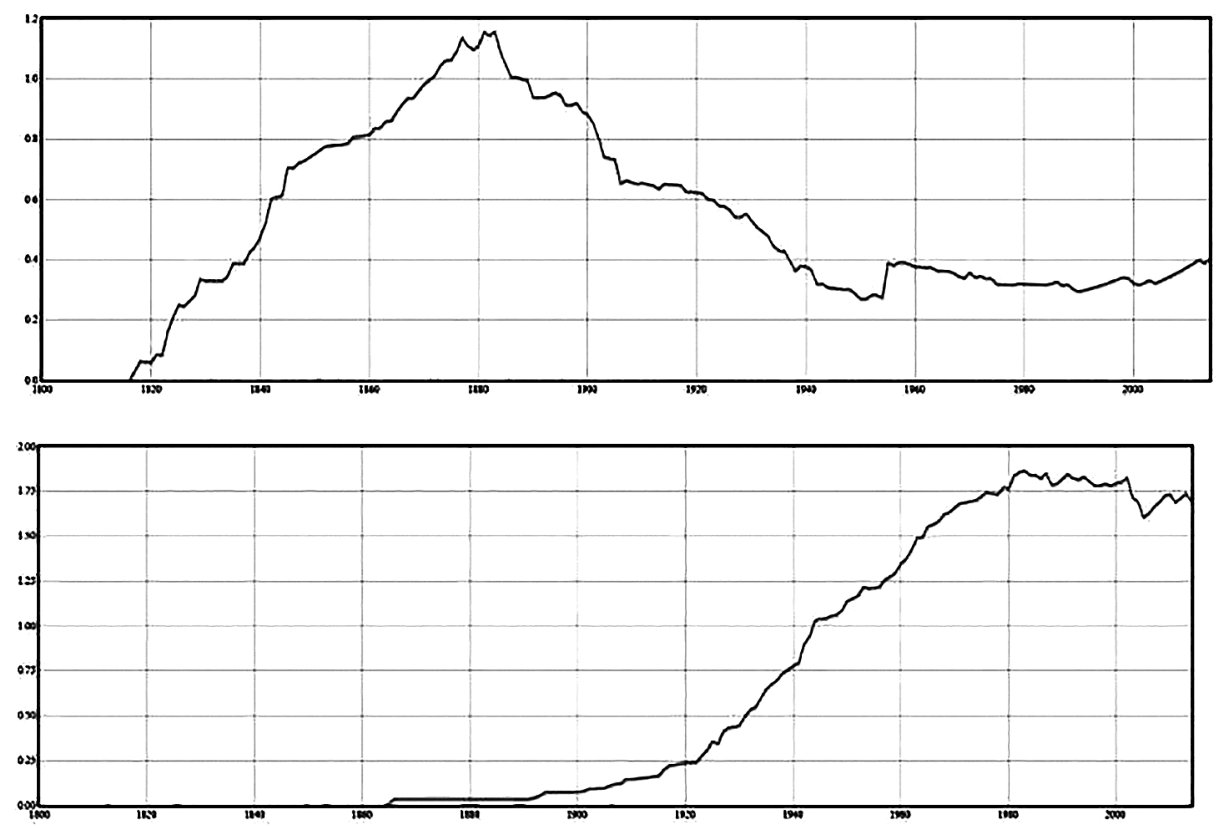

Рис. 2. Употребление формул почем я знаю и откуда я знаю 

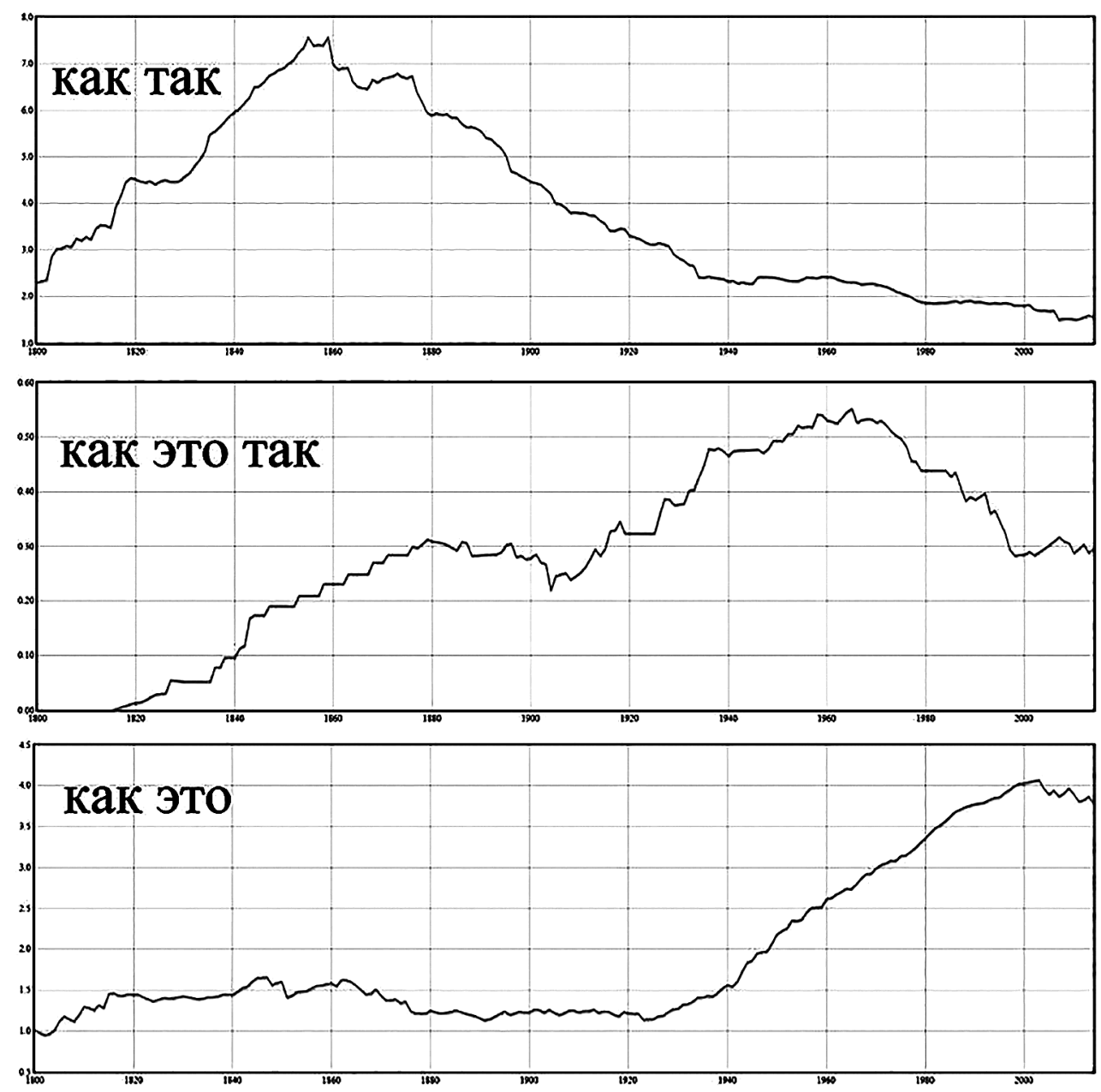

Рис. 3. Функционирование ДФ как так, как это так, как это

и прагматикой отказа от коммуникации помимо эмфатичности, как и почем я знаю, характеризуется еще и сниженностью. В этом смысле замена устаревшей лексемы на альтернативную действительно сохранила формулу в той функции, которая ей была свойственна прежде - что, по всей видимости, свидительствует о значимости этой функции как таковой.

Между тем устаревание конкретного элемента конструкции - не единственный стимул к изменению ДФ. Примером другого рода служит история формулы как так, в которой нет полнозначных устаревших компонентов - тем не менее, статистика НКРЯ показывает, что она постепенно уходит из употребления, конкурируя с как это и как это так с «равноценным» набором местоименных составляющих. 


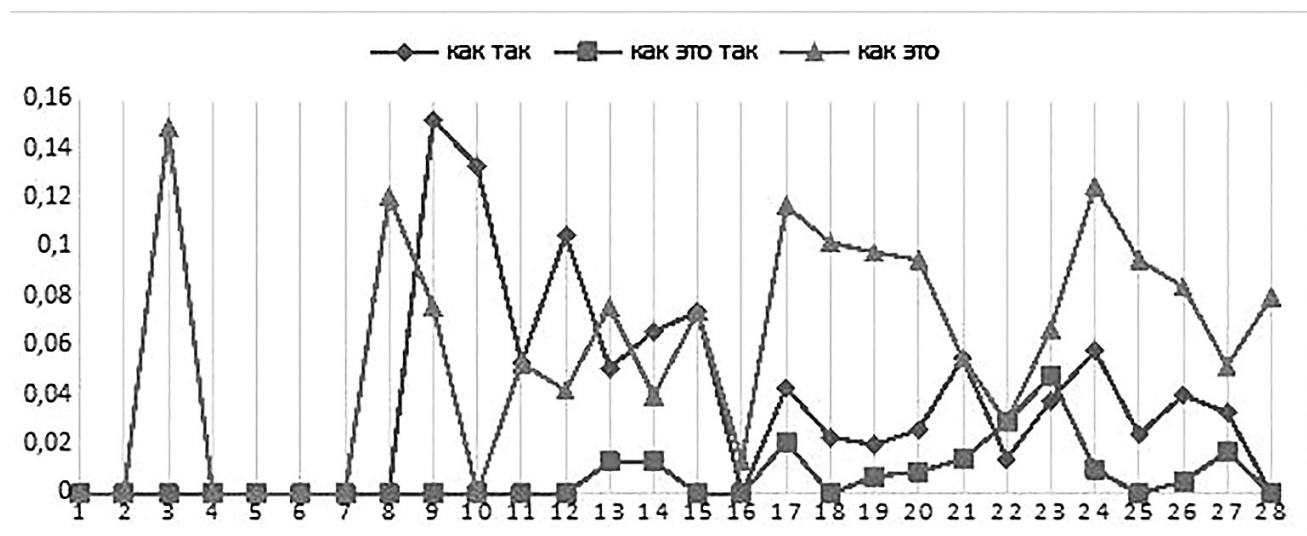

Рис. 4. Соотношение употребления ДФ как так, как это так, как это

При этом все три формулы к середине XX в. выражают одно и то же прагматическое значение удивления, недоумения из-за несоответствия сообщаемого тому, что знает собеседник или что он предполагал:

(6) - Поскольку моя практика была недостаточно длительной, я родился снова. Но уже не вампиром. Гера засмеялась, и ее смех был холодным и зльмм. Как так? - спросила она. - Вы нам только что цуельй час объясняли, что никакого «я» на самом деле нет. А потом говорите, что родились снова. [Виктор Пелевин. Бэтман Аполло (2013)].

(7) Тебе собирались позвонить! Не торопись, не делай ошибки! Пойми, я просто не успел объяснить. - Как это так? Чай выпить успел, опиум схватить успел, а главного не сказал? Убайдулла сунул острие лома в костер и начал его нагревать: - Чичас уши дыра делать. [Михаил Гиголашвили. Чертово колесо (2007)].

(8) Почему бы на это не купиться?.. - ... Игорь Рюрикович, не жалеете, что ушли с завода? - Я не ушел с завода. - Как это? Мы вроде с вами сейчас не на заводе, - я оглядываю кабинет в резиденции. Ни станков, ни кранов - стол, кресла, дорогая подставка для ручек. - Мне президент поручил работать. [Дарья Данилова, Дмитрий Карцев. Вышел в дамки // «Русский репортер», 2013].

Все эти формулы прошли примерно одинаковый путь от композиционального вопроса к удивлению, при этом они являются структурными вариантами одной единицы.

Из Рис. 4 видно, что в определенный момент все эти формулы обладают почти одинаковой частотой употребления, однако в дальнейшем частотность «как так» и «как это так» снижается, в то время как частотность формулы «как это» растет. Со временем в функции как так начинает употребляться формула как это, оказавшаяся более жизнеспособной, чем гибридная единица как это так. 


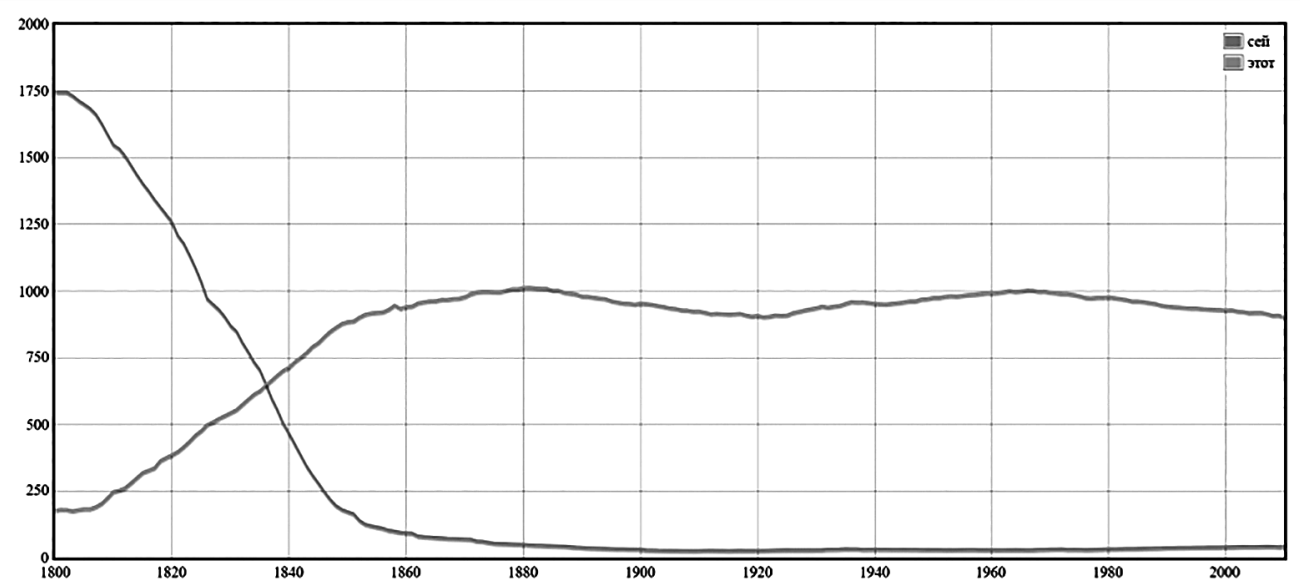

Рис. 5. Соотношение употребления местоимений сей и этот

Ясно, что динамика ДФ объясняется тем, что внутри вариантов одной формулы происходит перестройка с заменой компонентов, способных сохранить общее прагматическое значение формулы, при этом на смену менее частотному приходит более частотный элемент. С точки зрения статистики, это значит, что распределение частот диахронических вариантов ДФ должно напоминать распределение форм сей и этот (см. рис. 5), которые можно считать вариантами указательного местоимения и которые представлены в языке начала XIX века с явным преобладанием одного над другим. Затем, как видно из графика, тенденция меняется на противоположную: этот начинает успешно конкурировать с сей и в итоге получает преимущество.

Дизайн исследования заключался в следующем. Мы сгруппировали варианты одной ДФ таким образом, чтобы в разметке заключалось указание на то, что, например, а как иначе, а как же иначе; так что ж, ну так что и т. Д. относятся к одной и той же группе ДФ. Затем для каждого из вариантов были получены значения вхождений в корпусе за отдельные десятилетия, а после подсчитан коэффициент корреляции для каждой пары вариантов. Мы ожидали, что конкурирующие формы получат высокое отрицательное значение этого коэффициента. Это бы означало, что в тот момент, когда частотность одного варианта ДФ растет, частотность противопоставленного ему варианта должна падать и наоборот. Само по себе отрицательное значение коэффициента должно было подтверждать системные отношения вариантов ДФ во времени.

Однако на имеющихся у нас небольших данных наша гипотеза пока не подтвердилась статистически. Ожидаемый отрицательный коэффициент мы получили только в тех случаях, когда формулы довольно редки, что позволяет им «не пересекаться» во времени, однако при этом частота их употребления настолько мала, что мы не можем говорить, что полученная статистика свидетельствует о сменяемости структурных элементов. 


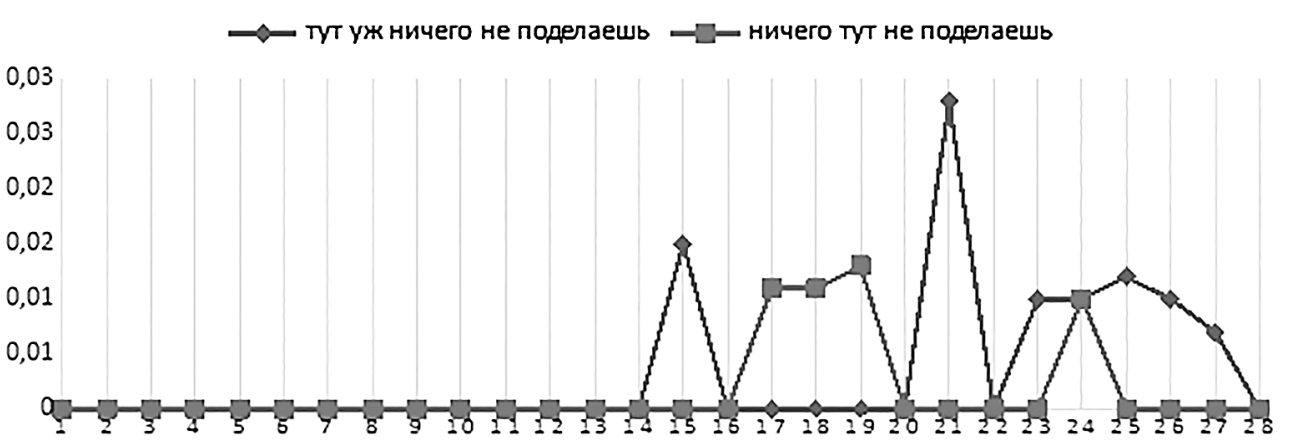

Рис. 6. Употребление формул тут уж ничего не поделаешь, ничего тут не поделаешь

Как показывает рис. 6, в течение интересующего нас периода варианты ДФ склонны существовать одновременно, по всей видимости, дополняя друг друга.

Тем не менее, кажется, что пример с формулами как так и как это не единичный и отражает некоторый глобальный процесс, связанный со слиянием значения формулы с формулой иной структурной организации, которая впоследствии становится более частотной и заменяет первоначальный вариант. Другое дело, что скорость этого процесса в разных случаях может быть разной — и для как так и как это она выше средней. Это значит, что наша гипотеза не подтвердилась из-за того, что для большинства формул временной промежуток, который был рассмотрен, оказался недостаточен для формальной статистической процедуры ${ }^{3}$.

В связи с этим интересными кажутся рис. 7 и рис. 8, отражающие соотношение вариантов в формулах да быть не может / не может такого быть и вот тото же / то-то вот. Правда, во втором случае оба варианта в итоге оказываются

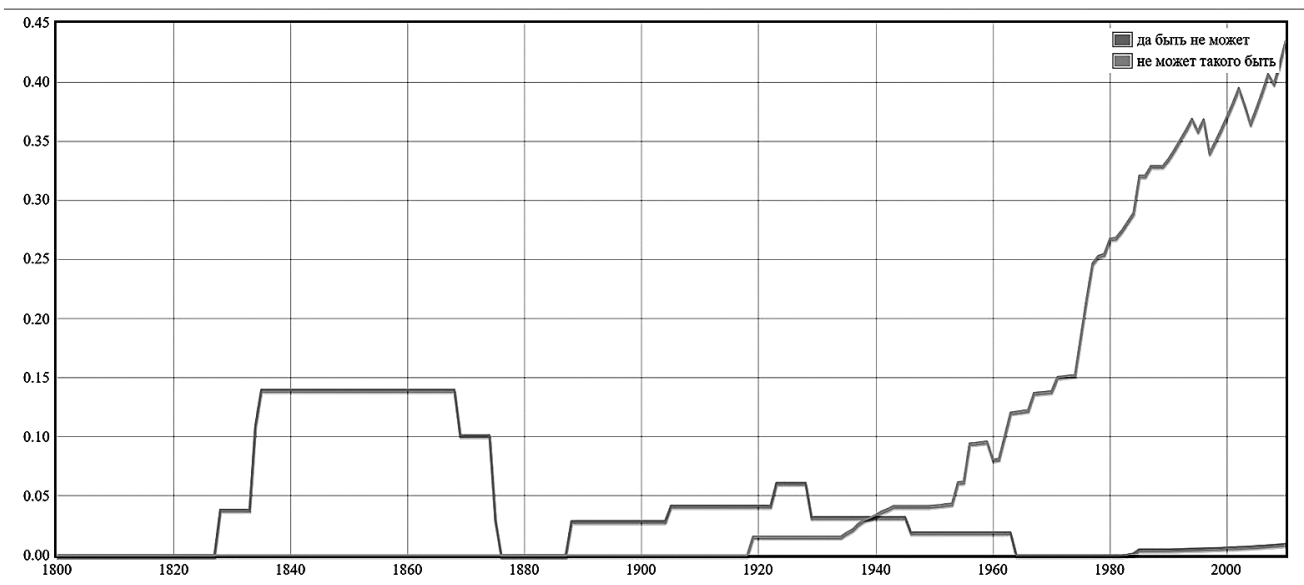

Рис. 7. Частотность употребления ДФ да быть не может, не может такого быть

${ }^{3} \mathrm{Cp}$. также большое количество «мнимых» нулей, получившихся в нашей таблице из-за округления значения вхождений формул в тех случаях, когда частота ДФ в целом по данным НКРЯ оказывается невысокой. 


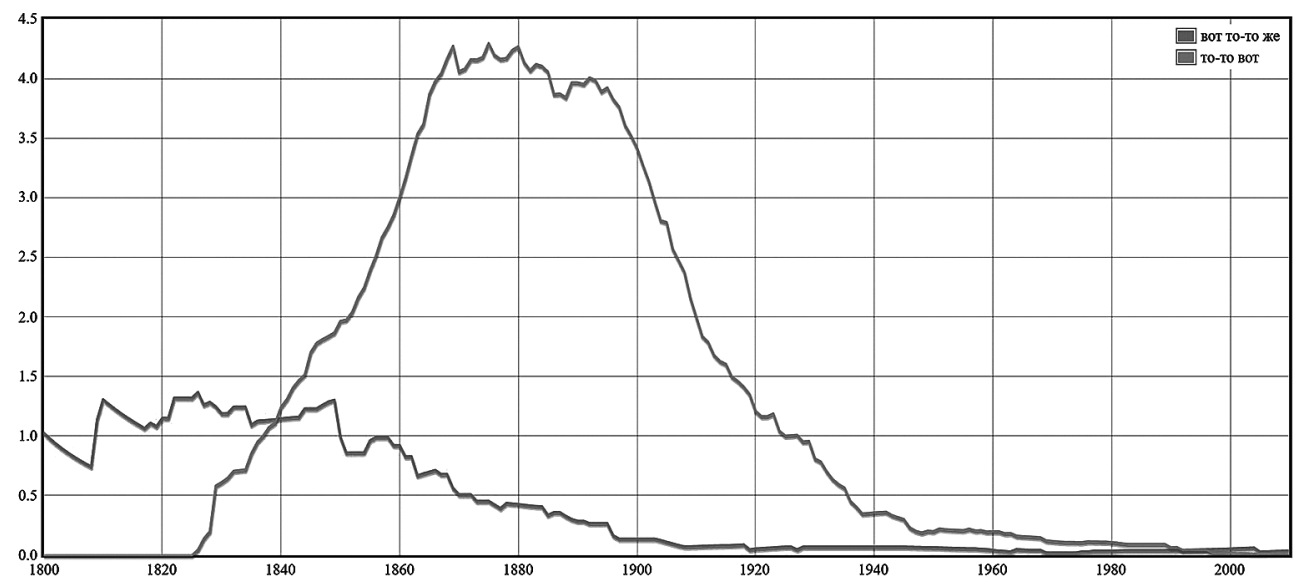

Рис. 8. Частотность употребления ДФ вот то-то же, то-то вот

устаревающими, однако на определенном этапе их сосуществования заметно доминирование одной единицы над другой.

В целом можно сказать, что высокая скорость прагматикализации ДФ не вызывают сомнений - хотя для их статистической визуализации при том наборе сегодняшних инструментов и при том объеме данных, которые собраны, не всегда хватает мощностей. Материал свидетельствует, что когнитивно значимые формулы не уходят бесследно - они замещаются своими вариантами. Главная задача — это полный анализ имеющегося материала, который позволит описать механизмы такого замещения: установить закономерности, которые которые лежат в основе процессов устаревания формулы, принципы выбора нового варианта и замены одного варианта на другой.

\section{4. Новые ДФ}

Новыми мы называем те ДФ, которые появляются преимущественно во второй половине XX в. или в более ранних текстах, после чего число их вхождений (по данным НКРЯ) продолжает расти, такие как: не факт, без проблем, что за дела, без вопросов и проч.

В качестве иллюстрации на рис. 9 представлена динамика употреблений ДФ не факт по данным НКРЯ. Из примеров видно, что в качестве формулы не факт появляется в 1970-е годы, и наш график показывает, что после этого частота его употребления заметно растет:

(9) А ножны с финкой на правом бедре... Левша?.. Не факт... [Владимир Богомолов. Момент истины (В августе сорок четвертого...) (1973)].

Само значение слова факт включает в себя не только идею соответствия Р действительности (10), как это написано в МАС [Евгеньева 1999], но и компонент оценки говорящего, утверждающий несомненность этого соответствия. Этот компонент объясняет семантику его сдвига в дискурсивную зону: МАС квалифицирует 


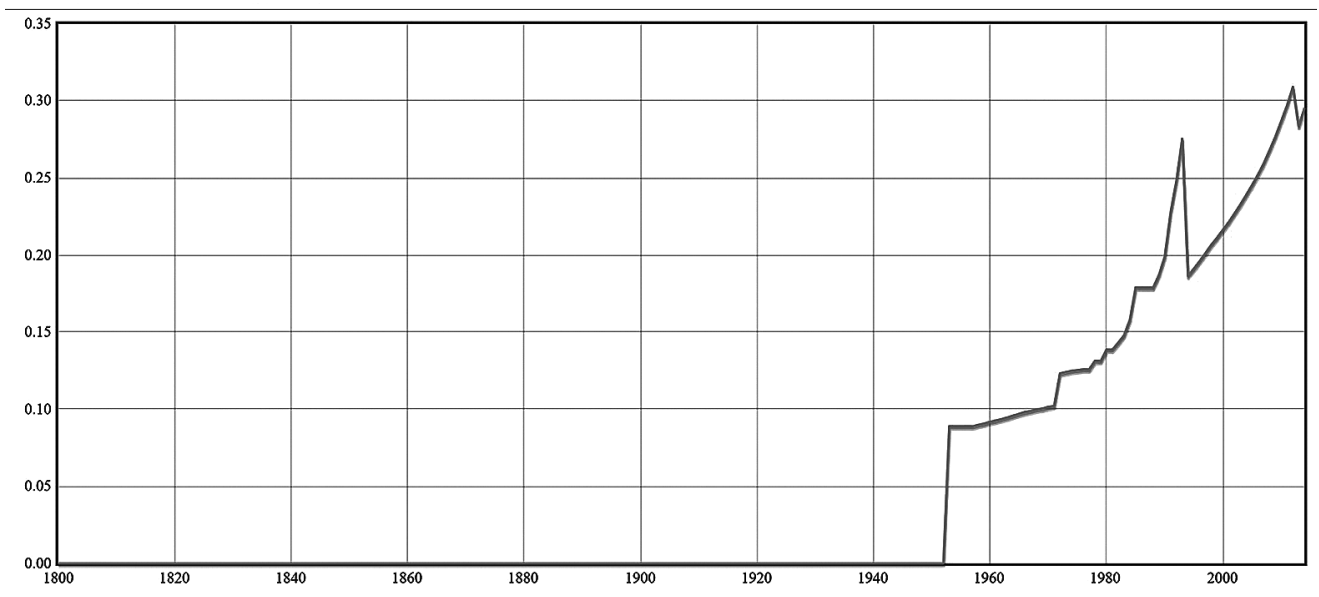

Рис. 9. Частотность употребления ДФ не факт

результирующую единицу как утвердительную частицу, синонимичную верно, несомненно и под. По данным НКРЯ, этот сдвиг произошел в 60-е годы ХІХ века (0,67 ipm), соответствующие ему изолированные употребления достигли пика в 1930 г. (3,06 ipm), а к концу XX в. значительно сократились (в период с 1980 по 2000 максимум $1 \mathrm{ipm})$.

(10) По крайней мере он хорошо знает этот важный исторический факт. [А. В. Никитенко. Дневник (1827)].

(11) - Ну, не все же пропадает, - возразила Лиза. - Факт. - Я, впрочем, не читала Прудона. [Н.С. Лесков. Некуда (1864)].

(12) - И ты с нами, окурок? - Факт! - ульгбулся Роман и поправил сползающий с плеча карабин. [Г.Г. Белых. Дом веселых нищих (1930)].

(13) И передовик так же говорит... Гнать, говорит, анкаголиков. Они показатели снижают. - Факт. [Михаил Анчаров. Как Птица Гаруда (1989)].

Между тем, как видно из рис. 9, ДФ не факт ведет себя совершенно иначе.

Первые его употребления (полнозначные, в единственном и множественном числе) - это контексты противопоставления, в которых отрицание относится не к истинности как таковой (и не дает значения 'ложь'): в сферу действия отрицания попадает оценочный компонент несомненности истины:

(14) <..> долгое время были в виду именно все одни только идеи, а не факты, за которые можно было бы ухватиться. [М. А. Корф. Записки (1838-1852).

Следующий шаг семантического развития - оценочный предикат с валентностью объекта: говорящий оценивает как недостоверную некоторую ситуацию Р. Р вводится придаточным с союзом что; такие контексты появляются в 1920-х годах и резко растут к концу XX в. (с 3 ipm до 11 ipm в начале XXI в.). Морфологический маркер этого этапа - запрет на формы множественного числа (15). 
(15) - Совсем не факт (*не факты), что пойдет за другого, - сказала Лена. [В. Ф. Панова. Спутники (1945).

Сомнение в утверждении собеседника - это как раз очень характерное значение из принадлежащих к так называемому «универсальному прагматическому набору» [Рахилина и др. 2019] — именно семантика сомнения запускает процесс превращения не факт в ДФ с этим значением. В конечном счете приобретение прагматического значения несогласия с предположением собеседника маркируется изменением синтаксиса: формула изолируется, объектную валентность можно не постулировать - по крайней мере она не выражается поверхностно, поскольку предположение становится частью дискурса другого участника диалога (16), (17).

(16) - Если б знал - поставил бы на него, что ли? - Не факт, - сказала Агата. [Андрей Лазарчук, Михаил Успенский. Посмотри в глаза чудовищ (1996)].

(17) Bот у кого их больше, тот и возглавит совет кредиторов. А значит, и протащит в арбитражном суде свою кандидатуру. - Тогда это будет банк «Орбита»! - Не факт! - не согласился Коломнин. - У банка всего пять миллионов. - Хорошенькое «всего». [Семен Данилюк. Бизнес-класс (2003)].

Как видим, слово факт дало жизнь двум (антонимичным) дискурсивным единицам: Факт! и Не факm! Первая появилась в середине XIX в. и уже выходит из употребления, тогда как вторая сформировалась на век позже: только к 70-м годам XX в. она стала использоваться как изолированная ответная реплика со значением несогласия. Однако разница не только в том, когда начался процесс их семантического изменения, но и в ходе самого процесса. Именно для отрицательной формы не факт характерна стадия превращения в предикат и приобретения валентности, которая выражается изъяснительным придаточным, и ее потеря как маркер превращения в ДФ. Похожий путь, по-видимому, проделало не суть, ср.:

(18) Лучшие, какие могут существовать приятели, Александры, не суть лучиие други, именно потому не суть, что они, как круглье, катятся ко всем, ни в кого не втыкаясь острым ребром, но и ни за кого не зацепляясь. [П.А. Флоренский. Имена (1926)].

(19) Как это работает? Не суть. Современнье технологии - итука сложная. [Свое кино (2004)],

а также многие другие новые формулы: их источником становятся полноценные конструкции оценки ситуации, у которых затем объект оценки из придаточного «переезжает» в предшествующую реплику, как бы обрезая исходную конструкцию справа. ср., например (20-23):

(20) С чего вы взяли, что получат отрицательный результат? [коллективный. Форум: Как врачи перелили годовалому ребенку ВИЧ-инфицированную кровь (2012)] $\rightarrow$ (Они) получат отрицательныц иезультат. - С чего вы взяли? 
(21) Ну и что с того, что параллельному классу досталась Лидия Тимофеевна? [Андрей Геласимов. Фокс Малдер похож на свинью (2001)] $\rightarrow$ Параллельному классу досталась Лидия Тимофеевна. - И что с того?

(22) Трудно сказать, по кому история с «Тремя столицами» и «Трестом» ударила сильнее. [Иван Толстой. Барин из Парижа // «Русская жизнь», 2012] $\rightarrow$ По кому история с «Тремя столицами» и «Трестом» ударила сильнее? Трудно сказать.

(23) Что поделать: картина пострадала в процессе бытования. [Дина Рубина. Белая голубка Кордовы (2008-2009)]. $\rightarrow$ Картина пострадала в процессе бытования - Что поделать!

Таким образом, по-видимому, внутри языка существуют какие-то стандартные модели, по которым образуются новые формулы. Однако есть и примеры внешнего заимствования, прямого калькирования ДФ непосредственно из языка-донора, как, например, это произошло с формулой нет проблем:

(24) <...>as her friend, I'm going to have to ask you to leave now $<\ldots>$ "Dude, no problem whatsoever. [Lauren Weisberger. The Devil Wears Prada (2003)].

(25) - Короче, как ее друг, я прошу тебя сейчас уйти. <...>. - Чувак, нет проблем. [Лорен Вайсбергер. Дьявол носит Прада (перевод М. Маяков, Т. Шабаева, 2006)].

ДФ Нет проблем появляется в текстах НКРЯ в середине 1960-х годов, однако в дальнейшем, по всей видимости, она служит источником для формул Какие проблемьт (конец 1970-х) и Без проблем (1980-е), которые строятся по уже существующим в языке моделям конструкций и формул, ср., например: $O$ чем ты говоришь! Какие деньги!, или: Без шансов / Без вопросов и под.

(26) Угу. Милорд, вы ведь им покажете? Покажете, да? - Какие проблемы! Сейчас отдохнем немного, перекусим, а потом как начнем мордовать всех подряд. Полетят клочки по закоулочкам! - Это будет только справедливо, - серьезно кивнула Лия, подтягивая к нам еду. [Андрей Белянин. Свирепый ландграф (1999)].

(27) - Ромыч, подбрось меня до церкви, а? - попросил Кирилл. - Без проблем. - Ть что, уходишь караулить? - удивился Валерий. - А что, Годовалов сейчас прийти не может? [Алексей Иванов (Алексей Маврин). Псоглавцы (2011)].

Как видим, здесь срабатывает обычный для заимствованных конструкций механизм «синтаксической имитации», который перестраивает их под известные говорящему шаблоны. 


\section{5. «Стабильные» ДФ}

К «стабильным» относятся дискурсивные формулы, которые продолжают использоваться на протяжении всего рассматриваемого периода, при этом сюда попадают и те ДФ, частота употребления которых может в значительной степени колебаться. В данном случае нам важно, что они не демонстрируют выраженной тенденции к спаду или увеличению частотности: в начале и в конце рассматриваемого периода они оказываются в практически равной степени частотными.

Например, в эту группу попадают слова, употребление которых оказывается неравномерным (представь себе, что это со мной и проч.), поэтому в определенный период количество текстов, включающих эти ДФ снижается. Так, в начале XIX в. частота единицы представь себе составляет 0,15 ipm, далее в 1920 -е гг. мы наблюдаем спад до 0,04 ipm, но к началу XXI в. частота этого сочетания составляет уже $0,19 \mathrm{ipm}$.

Первоначально, как и ожидалось, данное словосочетание употребляется в прямом значении:

(28) Сколько новых ошущений, какой разнообразный мир забав, радостей, удовольствий ожидают тебя в этом роскошном, обольстительном Париже! Представь себе... Вдруг барон замолчал, он поглядел робко вокруг себя и, схватив меня за руку, проговорил торопливо: [М.Н. Загоскин. Искуситель (1838)].

В 1920-е гг., когда мы наблюдаем спад употребления этой единицы, мы видим, что она уже оформилась как ДФ и используется как ответная реплика, служащая для подтверждения своих слов в предыдущем сегменте диалога:

- Какой Орлов? - Да нам чекист знаменитый! - Что ты говоришь? Представь себе! Поймали вчера на вокзале. Понесу-ка газетку Маргоше. Пусть отвлечется немножко. [Б.А. Лавренев. Рассказ о простой вещи (1924)].

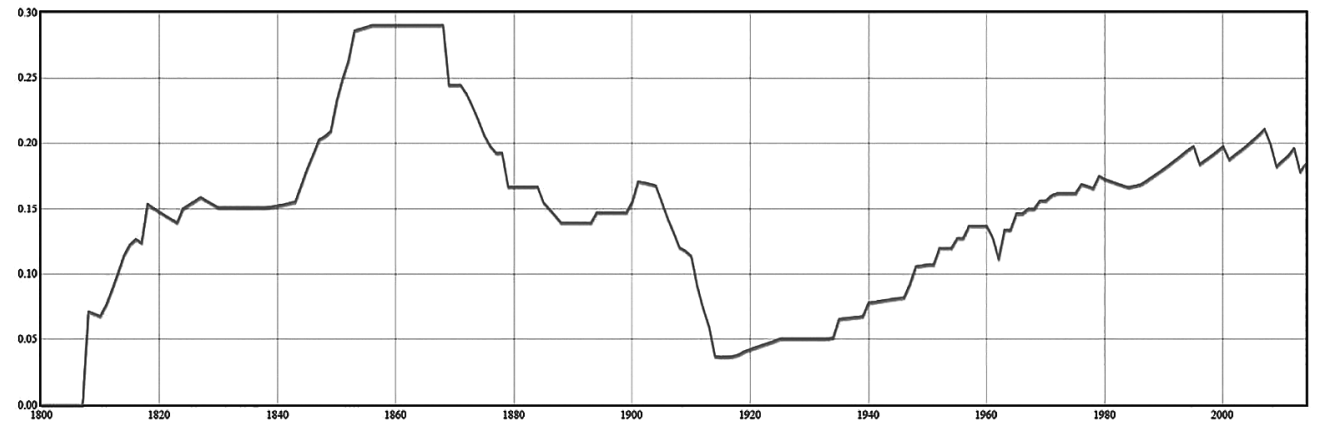

Рис. 10. Динамика употребления формулы представь себе 
Далее с 1970-х гг. ДФ представь себе начинает выражать просто подтверждение говорящим того, что удивляет его собеседника, заставляет его недоумевать:

- Что, подружились с ним за эту поездку? - спросил про Василия Ивановича Лева Степанов. - Представь себе. - Вы с ним или он с вами? Представь себе, и я с ним, и он со мной. - По-моему, вы первый - во всяком случае, у нас в редакции. [Константин Симонов. Так называемая личная жизнь/ Мы не увидимся с тобой... (1978)].

(31) Галя и так повсюду смотрит, был ты или нет? Думаешь, она не знала, что ты придешь? - A ты знала? - Представь себе. Да, знала, и я это чувствовал, я шел на зов. [Г. Я. Бакланов. Мой генерал // «Знамя», 1999].

Количество стабильных единиц, по результатам работы программы, составляет менее $10 \%$ от общего числа ДФ, однако нужно учесть, что эта группа выделена исключительно по формальному признаку неизменности частотности. Пример с представь себе свидетельствует, что она нуждается в дополнительном лингвистическом исследовании, потому что такой «стабильный» характер существования может оказаться иллюзией.

\section{6. Заключение и перспективы исследования}

В этой статье рассмотрен особый класс конструкций русского языка - класс дискурсивных формул - в целом, с диахронической точки зрения. ДФ носят преимущественно разговорный характер и достаточно эмфатичны - этим обусловлены два их важнейших свойства: высокая вариативность и необыкновенно высокая скорость изменения. Каждое из этих свойств имеет интересные в лингвистическом отношении аспекты, а кроме того, они тесно связаны друг с другом.

С одной стороны, по определению, ДФ имеют жесткую структуру и не содержат слотов, заполнение которых могло бы способствовать ее изменению. Одновременно, как и любые другие типы фразем [Баранов, Добровольский 2008], они допускают дополнительные эмфатические частицы и замену одних эмфатических компонентов на другие. Для ДФ как прагматических единиц такая вариативность особенно значима. С учетом этих возможностей, ДФ функционируют «семействами» (и для них это более характерно, чем для обычных конструкций), причем внутри семейства, ввиду того, что эти единицы гораздо более изолированны, чем обычные конструкции, сосуществуют полностью тождественные в отношении семантики и прагматики единицы. Это подтверждает наша статистика: часто у этих вариантов, по крайней мере некоторое время, нет очевидных статистических преимуществ друг перед другом.

С другой стороны, ДФ очень динамичны. Среди них почти нет стабильных, даже на временном отрезке в чуть более 200 лет можно увидеть оформление композиционального словосочетания в фиксированную в отношении формальной структуры единицу, и сопровождающее этот процесс вымывание первоначальной семантики и ее прагматикализацию. На том же выбранном нами небольшом 
временном отрезке можно наблюдать и устаревание формулы, и исчезновение из языка, а иногда и полный ее жизненный цикл, который, как это и должно быть у эмфатических единиц, недолог.

Общие контуры динамических процессов, которые были здесь проиллюстрированы, можно описать так. Формула может устаревать, во-первых, за счет устаревания определенного лексического компонента, а во-вторых, за счет «стирания» данной комбинации служебных элементов. Тогда ей на смену приходит структурно близкий вариант или более высокочастотный «член семейства». В последнем случае новая формула, которая ее замещает, состоит практически из тех же элементов. Что касается структурно новых ДФ, то для них есть разные источники, и здесь мы обсудили два: внутриязыковой и внеязыковой. Внутренним источником ДФ служат полноценные конструкции данного языка, в частности конструкции оценки некоторого события, его достоверности, вероятности, последствий и проч. Такого рода конструкции легко разделяются на презумптивную часть, которая становится предшествующей репликой собеседника, и ассертивную, которая прагматикализуется и превращается в формулу. Внешним источником служит заимствование и калькирование, в ходе которого, однако, как мы показали, все равно включаются внутренние механизмы русского языка.

Ближайшая задача нашего исследования - уточнить детали исторических изменений, которые претерпевают ДФ, представляющие разные структурные и семантические классы.

\section{Литература}

Баранов А.Н., Добровольский Д.О. Аспекты теории фразеологии. М. : Знак, 2008.

Булаховский Л.А. Русский литературный язык первой половины XIX века. Киев : Радянська школа, 1948.

Бычкова П.А., Рахилина Е.В., Слепак Е.А. Дискурсивные формулы, полисемия и жестовое маркирование // Труды Института русского языка им. В. В. Виноградова. 2019, № 21. С. 256-283.

Виноградов В.В., Шведова Н. Ю. Очерки по исторической грамматике русского литературного языка XIX века. М. : Наука, 1964.

Два века в двадцати словах / Отв. ред.: М. А. Даниэль, Н. Р. Добрушина. М.: Изд. дом НИУ ВШЭ, 2016.

Добровольский Д. О. К динамике узуса (язык Пушкина и современное словоупотребление) // Русский язык в научном освещении. 2001. № 1. С. 161-178.

Зализняк Анна A. Об эффекте ближней семантической эволюции // PHILOLOGICA. Двуязычный журнал по русской и теоретической филологии. 2012. Т. 9. № 21/23. С. 11-22.

Падучева E. B. Из наблюдений над языком Л. Толстого (к вопросу о малых диахронических сдвигах) // Вопросы языкознания. 2018. № 5. C. 49-63. DOI: 10.31857/ S0373658X0001396-4. 
Пеньковский А.Б. Загадки пушкинского текста и словаря. Опыт филологической герменевтики. М.: Языки славянских культур, 2005.

Рахилина E. В. Говорю я, Карл // Компьютерная лингвистика и интеллектуальные технологии. По материалам международной конференции «Диалог'2017». Вып. 16 (23). М.: РГГУ, 2017. С. 361-369.

Рахилина Е.В., Кузнецова Ю.Л. Грамматика конструкций: теория, сторонники, близкие идеи // Лингвистика конструкций / Под ред. Е. В. Рахилиной. М.: Азбуковник, 2010. С. 18-79.

Рахилина Е.В., Резникова Т.И., Бородина М.А. «Тамань сегодня»: корпусное исследование русского языка XIX века. Труды Института русского языка им. В.В. Виноградова, Вып. 11, 2016.

Русский язык: конструкционные и лексико-семантические подходы 2017 (RusConstr). Тезисы конференции 2017 г. $\quad$ URL: https://iling.spb.ru/confs/ rusconstr2017/papers.html

Словарь русского языка. В 4-х т. / Под ред. А. П. Евгеньевой. 4-е изд., стер. М., 1999.

Шаронов И. А. Коммуникативы как функциональный класс и как объект лексикографического описания // Русистика сегодня, № 2, 1996, с. 89-112.

Aijmer, $K$. Conversational Routines. Convention and Creativity. Longman, London. 1996.

Coulmas, F. Conversational Routine: Explorations in Standardized Communicative Situations and Prepatterned Speech. The Hague, Mouton. 1981.

Fillmore, Ch. J. The mechanisms of "construction grammar" // Annual Meeting of the Berkeley Linguistics Society. Berkeley, 1988. Vol. 14. P. 35-55.

Fillmore, Ch.J., Kay, P. Construction Grammar Course Book. Berkeley: University of California, 1992.

Fillmore, Ch.J. Remarks on contrastive pragmatics // Contrastive linguistics: Prospects and problems. 1984. P. 119-141.

Gerasimenko E., Puzhaeva S., Zakharova E., Rakhilina E. Defining discourse formulae: computational approach (in press)

Hilpert, M. Constructional change in English: Developments in allomorphy, word formation, and syntax. - Cambridge University Press, 2013.

Hoffmann, T., Trousdale, G. (Eds.). The Oxford handbook of construction grammar. Oxford: Oxford University Press, 2013.

Hopper, P. J., Traugott, E. C. Grammaticalization. Cambridge: Camdridge University Press, 2003 [1993].

Janda, L.A., Lyashevskaya, O., Nesset, T., Rakhilina, E., Tyers, F. M. A Constructicon for Russian: Filling in the Gaps. Constructicography: Constructicon development across languages. Amsterdam: John Benjamins. 2018. P. 165-182.

Kuzmenko E., Kutuzov A. Two centuries in two thousand words: neural embedding models in detecting diachronic lexical changes // Quantitative Approaches to the Russian Language. Routledge, 2017. P. 105-122. 
Lubimovka (2018). The Lubimovka Young Russian Playwrights Festival. Available at http://lubimovka.ru/piesy (accessed January 2019).

Mey, J. Pragmatics. Blackwell, Oxford. 2001.

Russian Drama Corpus (2018). Available at https://github.com/lehkost/RusDraCor/ tree/master/tei (accessed January 2019).

Wray, A. Formulaic Language and the Lexicon. Cambridge: Cambridge University Press. 2002.

\author{
${ }^{1}$ S. Zhukova, ${ }^{1}$ B. Orekhov, ${ }^{1,2}$ E. Rakhilina \\ ${ }^{1}$ National Research University Higher School of Economics \\ ${ }^{2}$ V.V. Vinogradov Russian Language Institute of the Russian Academy of Sciences \\ (Russia, Moscow) \\ syupuzhaeva@gmail.com,nevmenandr@gmail.com,rakhilina@gmail.com
}

\title{
DISCOURSE FORMULAE IN RUSSIAN: DIACHRONIC APPROACH
}

This article deals with the description of Russian discourse formulae in diachronic perspective. Discourse formulae are defined as easily reproduced phraseological constructions mostly used as isolated responds in the dialogs. Unlike traditional constructions, they do not have variables in their structure. The preceding remark of an interlocutor is what serves as a construction slot. Being emphatic and semantically bleached, discourse formulae are extremely dynamic diachronically, the changes of their form and semantics are observable even within a short span oftime, like two centuries. To get this diachronic information the list of Russian discourse formulae relevant for 19-20 centuries was arranged statistically by frequencies for every 10-years. Examples of old, obsolete formulae, new formulae which appeared recently and those which seem to be stable in frequency for the last two centuries, have been thoroughly analyzed. Through these examples one could see the mechanisms of pragmaticalization of a compositional word combination (i.d. turning it into fixed idiomatic expressions with pragmatic meanings), and also the reasons for formulae becoming obsolete and the origin of their structural and semantic instability.

Key words: Discourse formulae, diachronic studies, corpus linguistics, Construction grammar, Russian Constructicon, discourse of drama

\section{References}

Aijmer, K. Conversational Routines. Convention and Creativity. Longman, London. 1996.

Baranov A. N., Dobrovol'skij D. O. Aspekty teorii frazeologii [Aspects of the theory of phraseology]. Moscow, "Znak" Publ., 2008. (In Russ.)

Bulakhovskii L.A. Russkii literaturnyi yazyk pervoi poloviny XIX veka [The Russian literary language of the first half of the 19 century]. Kyev, Radyans'ka shkola Publ., 1948. (In Russ.) 
Bychkova P.A., Rakhilina E.V., Slepak E.A. [Discourse formulae, polysemy and gesture marking] // Trudy Instituta russkogo yazyka im. V. V. Vinogradova [Proceedings of V.V. Vinogradov Russian language Institute]. 2019, no. 21, pp. 256-283. (In Russ.)

Coulmas, F. Conversational Routine: Explorations in Standardized Communicative Situations and Prepatterned Speech. The Hague, Mouton. 1981.

Dobrovol'skij D.O. [On the dynamics of usage (Pushkin's language and modern usage)]. Russkii yazyk v nauchnom osveshchenii. 2001, no. 1, pp. 161-178. (In Russ.)

Dva veka vdvadtsati slovakh [Two centuries in twenty words] / M. A. Daniehl', N. R. Dobrushina (eds.). Moscow, NRU Higher School of Economics Publ. House, 2016. (In Russ.)

Fillmore, Ch. J. The mechanisms of "construction grammar" // Annual Meeting of the Berkeley Linguistics Society. Berkeley, 1988. Vol. 14, pp. 35-55.

Fillmore, Ch. J., Kay, P. Construction Grammar Course Book. Berkeley: University of California, 1992.

Fillmore, Ch. J. Remarks on contrastive pragmatics // Contrastive linguistics: Prospects and problems. 1984, pp. 119-141.

Gerasimenko E., Puzhaeva S., Zakharova E., Rakhilina E. Defining discourse formulae: computational approach (in press).

Hilpert M. Constructional change in English: Developments in allomorphy, word formation, and syntax. Cambridge University Press, 2013.

Hoffmann T., Trousdale G. (Eds.). The Oxford handbook of construction grammar. Oxford: Oxford University Press, 2013.

Hopper P. J., Traugott E.C. Grammaticalization. Cambridge: Camdridge University Press, 2003 [1993].

Janda, L. A., Lyashevskaya, O., Nesset, T., Rakhilina, E., Tyers, F. M. A Constructicon for Russian: Filling in the Gaps. Constructicography: Constructicon development across languages. Amsterdam: John Benjamins. 2018, pp. 165-182.

Kuzmenko E., Kutuzov A. Two centuries in two thousand words: neural embedding models in detecting diachronic lexical changes // Quantitative Approaches to the Russian Language. Routledge, 2017, pp. 105-122.

The Lubimovka Young Russian Playwrights Festival. Available at http://lubimovka. ru/piesy (accessed January 2019).

Mey, J. Pragmatics. Blackwell, Oxford. 2001.

Paducheva E.V. [Some remarks on the language of Leo Tolstoy and small-scale diachronic shifts]. Voprosy Yazykoznanija. 2018, no. 5, pp. 49-63. DOI: 10.31857/ S0373658X0001396-4. (In Russ.)

Pen'kovskii A.B. Zagadki pushkinskogo teksta i slovarya. Opyt filologicheskoi germenevtiki [Mysteries of Pushkin's text and vocabulary. An attempt of philological hermeneutics]. Moscow, Yazyki Slavyanskikh Kul'tur Publ., 2005. (In Russ.)

Rakhilina E. V. [I say, Carl]. Komp'yuternaya lingvistika i intellektual'nye tekhnologii. Po materialam mezhdunarodnoi konferentsii "Dialog'2017". [Computational Linguistics and Intellectual Technologies. Papers from the Annual International Conference "Dialogue"]. No. 16 (23). Moscow, Russian State Univ. for the Humanities, 2017, pp. 361-369. (In Russ.) 
Rakhilina E. V., Kuznetsova Yu. L. [Introduction. Construction Grammar: Theories, Adherents, Similar Approaches]. E. V. Rakhilina (Ed.). Lingvistika konstruktsiy [Construction linguistics]. Moscow: Azbukovnik Publ., 2010, pp. 18-79. (In Russ.)

Rakhilina E.V., Reznikova T.I., Borodina M. A. ["Taman today": corpus case study of the Russian language of the XIX ${ }^{\text {th }}$ century]. Trudy Instituta russkogo yazyka im. V.V. Vinogradova [Proceedings of V.V. Vinogradov Russian language Institute]. Vol. 11. 2016, pp. 240-253. (In Russ.)

Russian Drama Corpus. Available at https://github.com/lehkost/RusDraCor/tree/ master/tei (accessed January 2019).

Russian language: constructional and lexical-semantic approaches (RusConstr) 2017. Abstracts. Available at https://iling.spb.ru/confs/rusconstr2017/papers.html

Sharonov I. A. [Communicatives as a functional class and the object of lexicographical description] // Rusistika segodnia [Russian studies today]. 1996, no. 2, pp. 89-112. (In Russ.)

Slovar' russkogo iazyka [The Russian language dictionary]. In 4 v. / A.P. Evgen'eva (ed.). Moscow, 1999. Available at http://feb-web.ru/feb/mas/ (In Russ.)

Vinogradov V.V., Shvedova N.Yu. Ocherki po istoricheskoi grammatike russkogo literaturnogo yazyka XIX veka. [Essays on the historical grammar of the Russian literary language of the 19th century]. Moscow, Nauka Publ., 1964. (In Russ.)

Wray, A. Formulaic Language and the Lexicon. Cambridge: Cambridge University Press. 2002.

Zaliznyak Anna A. [On the effect of small-scale semantic evolution]. PHILOLOGI$C A$. Dvuyazychnyi zhurnal po russkoi i teoreticheskoi filologii [PHILOLOGICA. Bilingual journal on Russian and theoretical Philology]. 2012. Vol. 9, no. 21/23, pp. 11-22. (In Russ.) 